ASM Sc. J., 13, 2020

https://doi.org/10.32802/asmscj.2020.sm26(1.16)

\title{
Non-Stationary in Extreme Share Return: World Indices Application
}

\author{
Muhammad Fadhil Marsani ${ }^{1,2}$ and Ani Shabri ${ }^{1}$ \\ ${ }^{1}$ Department of Mathematical Science, Faculty of Science, Universiti Teknologi Malaysia, \\ 81310 UTM Johor Bahru, Johor, Malaysia \\ ${ }^{2}$ School of Mathematical Sciences, Universiti Sains Malaysia, 11800 Minden, Penang, Malaysia
}

\begin{abstract}
This paper investigates the behaviour of the extreme share return for the 26 different major indices shares by exploring their stationarity. Extreme return for weekly and monthly series is generated by using block maxima method. Four-employed test permits us to spot non-stationarity in extreme movement. The Augmented Dickey-Fuller and Kwiatkowski Phillips Schmidt Shin (KPSS) test scanned the unit root and the stationarity, and Mann-Kendall and Spearman's test inspected the trend and correlation in the series. Our approach approximates global stock returns for weekly and monthly series market activity. We find most of the extreme stock to be active in shift movement, and we have confirmed that the movement of extreme share return for the majority of the stock indices in the weekly and monthly interval is nonstationary. This testified statistical property in the series can be used as the first crucial appraisal when scrutinizing extreme share return for future research.
\end{abstract}

Keywords: Extreme share returns; block maxima method; non-stationary; stock market; major indices

\section{INTRODUCTION}

The uncertainty in stock return is a fundamental concept of risk encountering by an investor in the share market. The risk in is profoundly influenced by extreme volatility movement, and the magnitude of risk rely on statistical properties, e.g. the stationarity, tail, skewness and kurtosis. Most research on risk measurement portfolio has been carried out by setting in stationarity idea or fluctuation stability throughout time see (Jensen 1969; Kon \& Jen 1978; Roll 1977). The stationary process can be termed as a stochastic process associated with unrestricted joint probability distribution constant over the time. On the other hand, non-stationary in the time series defined as an alteration in mean, variances and covariance either with the existence of random walks, trends, cycle or mixture of it. Non-stationary comportment suggests that the series has an unfixed mean by diverting away from initial time range over the time. A critical aspect of non-stationary in time series is the series random and unpredictable since substantial variation in the series made it difficult to clarify. In this respect, an element of random processes by the existence of non-stationary behaviour in the series may trouble the statistical inference relating the time series paradigms. Rozelle and Fielitz (1980) state that probability distributions of past share returns should provide consideration on the series stationarity. This view is parallel with Hsu (1984) which points out that the idea of risk and the components that clarifying risk are incredibly unclear in monetary theories, poor comprehension in the character of risk or series fluctuation, made it hard to grasp the share return behaviour. For this, it is vital for the investor to comprehend stationarity in extreme time series before formulating an accurate projection.

Since the 1970s, non-stationarity of time series has been at the centre of much attention. Black and Scholes (1973) in their comparative study state that pricing models for share options frequently require adequate measurement of the stationarity in the variance to create proper estimates of

*Corresponding author's e-mail: fadhilmarsani@gmail.com 
share return. Nelson and Plosser (1982) presented a discussion on the importance of considering non-stationery and unit root properties in the analysis. They inspect historical time series to study the significance of real factor element in economic volatility using the Dickey-Fuller testing method and conclude that a basis of stationary fluctuations cannot clarify the enormous portion of output discrepancy, although real factors with the foundation of the nonstationary module may offer a definite function in output oscillations. Perron (1988) state that the character of the nonstationarity in the series caused by the existence of a unit root, this presence suggests a stochastic non-stationary as opposed to a deterministic trend. He remarked that existence of a nonstationary in the series frequently has theoretical effect in the model and suggest making use of information available.

Recently, researchers have adopted the importance of nonstationarity behaviour in a financial and monetary economics data. Study on time series model and analysis suggest that it is not appropriate to employ methods invented for stationary series on non-stationary series as a result is always deceiving (Nason, 2006). Stărică and Granger (2005) give some reliable methods for analysing daily stock returns by abandoning the idea of global stationarity. They have established that the daily stock return behaviour is nonstationarity, uncorrelated and homoscedastic. Also, it has commonly been stressing the existence of stationarity and unit root properties in the analysis see (Behr and Pötter, 2009; Masood et. al., 2010; Khan, 2011; Birău and Trivedi, 2013; Petrică, Stancu and Tindeche, 2016; Petrică, Stancu and Ghițulescu, 2017). Taken together, literature supports the notion that non-stationarity behaviour in time series evokes critical examination before one developing the statistical models. The existence of a nonstationarity has an inevitable effect on the methodology consumed in the later interpretation. There is a risk in every series fluctuation, and this information can be extracted in terms of statistical interpretation.

So far, there has been little discussion about the stationary condition in extreme return environment. The rationale for the present study is to confirm the movement of the worldwide extreme share return whether it is significantly stationary or not since the impact of having non-stationary in time series analysis may lead to a spurious and unreliable result. Our work is stimulated by increasing sign of uncertainty in the qualities of share returns and swollen recognition of the effects when adopting inaccurate stationarity assumption while analysing the series. Based on recent literature see (Tolikas, 2014; Hussain \& Li, 2015; Marsani, Shabri \& Jan, 2017) that has drawn massive attention on the analysis of share return using Extreme Value Theory (EVT) has inspired us to investigate the stationarity behaviour in the extreme share returns for the global stock indices.

Stationarity validation in extreme share return in global stock indices still not inclusive and ought further consideration. Extreme share return fluctuation movement has not yet to be understood, and this study seeks to obtain validation. The study presented here is one of the first investigations to examine in detail the stationarity in extreme stock return by addressing how can one endorse extreme share returns is theoretically nonstationarity. The objective of our approach is detecting the non-stationarity for the extreme series period using nonstationarity tests and trend analysis. The primary instrument in recognising the nonstationary behaviours in the series is by using the Augmented Dickey-Fuller (ADF) and Kwiatkowski Phillips Schmidt Shin (KPSS) test to scan for unit root and stationarity. MannKendall and Spearman's analysis will be used to inspect the trend and correlation in the series. Therefore, this study makes a major contribution to developing risk management by demonstrating 26 global stock indices in clarifying the stationarity in extreme stock return that has been less perceived in the analysis.

\section{MATERIALSANDMETHODS}

\section{A. Data Description}

The stock market indices comprise various share markets around the world. Twenty-six set of global share price namely ^ooooo1 (SSE Composite Index), ^AORD (ALL ORDINARIES), ^AXJO (S\&P/ASX 200), ^BFX (BEL 20), ${ }^{\wedge}$ BSESN (S\&P BSE SENSEX), ^BVSP (IBOVESPA), ^DJI (Dow 30), ${ }^{\wedge}$ FCHI (CAC 40), ${ }^{\wedge}$ GDAXI (DAX PERFORMANCE-INDEX), ^GSPC (S\&P 500), ^GSPTSE (S\&P/TSX Composite index), ^ HSI (HANG SENG INDEX), ${ }^{\wedge}$ IXIC (Nasdaq), ^JKSE (Jakarta Composite Index), ^KS11 (KOSPI Composite Index), ^ MERV (MERVAL), ^ MXX (IPC MEXICO), ^N1Oo (EURONEXT 100), ^N225 (Nikkei 225), ${ }^{\wedge}$ NYA (NYSE COMPOSITE (DJ)), ^RUT (Russell 2000), ${ }^{\wedge}$ STOXX50E (ESTX 50 PR.EUR), ^ ${ }^{\wedge}$ TWII (TSEC weighted index), ${ }^{\wedge} \mathrm{VIX}$ (Vix), ${ }^{\wedge} \mathrm{XAX}$ (NYSE AMEX COMPOSITE INDEX), and ${ }^{\wedge} \mathrm{KLSE}$ (FTSE Bursa Malaysia KLCI) is 
obtained from yahoo finance source. The sample of the secondary data has been taken according to major stock price indices seeing as investor always consult this as the benchmarks to measure the current performance of the market. To be consistent, each of the global share price data is standardized by taking out from 2000 to 2017 (17 years). The extreme value theory (EVT) method applied to generate weekly and monthly extreme share return.

\section{B. Block Maxima-Minima}

In extreme value theory, there are two primary methods generally applied namely the block maxima-minima method (BMM) and the peaks over threshold (POT) method. In this paper, we opt only for BMM because this approach is outrivalled in demonstrating extreme share price volatility for a given interval. For a weekly and monthly interval, the maximum and minimum series developed after a chosen block ( $m$ ) of 5 and 20 trading days for weekly and monthly respectively. For maximum return, this approach can be written as:

$$
\begin{aligned}
& x_{1}=\max \left(R_{1}, R_{2}, \ldots, R_{m}\right), \\
& x_{2}=\max \left(R_{m+1}, R_{m+2}, \ldots, R_{2 m}\right) \\
& \mathrm{M} \\
& x_{n / m}=\max \left(R_{n-m}, R_{n-m+1}, \ldots, R_{n}\right)
\end{aligned}
$$

$x$ is extreme maximum return in each block, $R$ stand for daily share returns, $n$ denote total sample observation, $m$ is the size of the timespan block, and $n / m$ is the last maximum observation of extreme return.

\section{Trend}

To produce a precise model, comprehending statistical properties of the empirical data is crucial. For that, unit root and stationarity examination used to inspect the trend, random walks and cycle. In this study, nonparametric methods are apposite for non-normally distributed data and censored data which commonly encountered in share return series see (Fama, 1965; Gray and French, 1990; Peiro, 1994; Theodossiou, 1998).

\section{Mann-Kendall (MK)}

The non-parametric Mann-Kendall test is used to spot monotonic trends in series with a hypothesis,

\section{$H_{0}$ : No monotonic trend in the data series $V S$ $H_{1}$ : Data series follow a monotonic trend}

The Mann-Kendall test statistic $S$ computed from this equation:

$$
S=\sum_{k=1}^{n-1} \sum_{j=k+1}^{n} \operatorname{sign}\left(X_{j}-X_{i}\right)
$$

where $x_{j}$ are the sequential data values, $n$ is the length of the data set with,

$$
\operatorname{sign}(x)=\left\{\begin{array}{c}
1 \text { if } x>0 \\
0 \text { if } x=0 \\
-1 \text { if } x<0
\end{array}\right.
$$

The mean $E[S]=0$ and the variance $\sigma^{2}[S]$ is asymptotically normal given as,

$$
\sigma^{2}[s]=\left\{n(n-1)(2 n+5)-\sum_{j=1}^{p} t_{j}\left(t_{j}-1\right)(2 t+5)\right\} / 18
$$

where $t_{j}$ is the number of data points in the $j$ th attached group. The Z-transformation denoted by:

$$
Z=\left\{\begin{array}{c}
\frac{S-1}{\sigma} \text { if } S>0 \\
0 \text { if } S=0 \\
\frac{S+1}{\sigma} \text { if } S<0
\end{array}\right.
$$

Moreover, the statistic $S$ is strongly related to Kendall's $\tau$ as,

$$
\tau=\frac{S}{D}
$$




$$
\left.D=\left[\frac{1}{2} n(n-1)-\frac{1}{2} \sum_{j=1}^{p} t_{j}\left(t_{j}-1\right)\right]^{1 / 2}\left[\frac{1}{2} n(n-1)\right]^{1 / 2}\right)
$$

\section{Spearman's rho (SR)}

Spearman's rho (SR) test is an additional non-parametric rank-order test to spot the trend. The hypothesis is given as,

$$
H_{0} \text { : all the } X_{i} \text { are independent and identically distributed }
$$$$
H_{1}: X_{i} \text { increases or decreases with } i
$$

The test statistic as following,

$$
D=1-\frac{6 \sum_{i=1}^{n}\left[R\left(X_{i}\right)-i\right]^{2}}{n\left(n^{2}-1\right)}
$$

where $\left\{X_{j}, i=1,2, \ldots, n\right\}$ is sample data set, $R\left(X_{i}\right)$ is the rank of $i$ th observation $X_{i}$ in the sample of size $n$.

$$
\begin{gathered}
E(D)=0 \\
V(D)=\frac{1}{n-1}
\end{gathered}
$$

the mean and variance for test statistic $D$ written above are approximately normally distributed. The following standardized statistic Z,

$$
Z_{S R}=\frac{D}{\sqrt{V(D)}}
$$

follows the standard normal distribution $Z \sim N(0,1)$.

\section{Nonstationarity Analysis}

Next, three approaches used to check the existence of nonstationarity in the series that is Augmented Dickey-Fuller (ADF) and Kwiatkowski Phillips Schmidt Shin (KPSS).

\section{The Augmented Dickey-Fuller test}

Augmented Dickey-Fuller test (ADF) is one of the most common procedures for determining unit root in atime series sample. The hypothesis for ADF test is,

$$
\begin{aligned}
& H_{0} \text { : unit root is present in a time series sample/ } \\
& \text { non-stationary } \\
& H_{1}: \text { no unit root }
\end{aligned}
$$

The ADF statistic is always representedby a negative value, more negative the value suggesting higher chances for null hypothesis rejection. ADF statistic can be defined as this model:

$$
z_{t}=\rho z_{t-1}+y_{t}^{\prime} \delta+\varepsilon_{t}
$$

where $\rho$ and $\delta$ are the two parameters for estimation, $\varepsilon_{t}$ is a random disturbance, and $y_{t}$ is the independent term which allowed to have a constant, a trend, or both constant and a trend. A time series $z$ is assumed to be non-stationary if the estimated parameter $\rho$ is larger than or equal to 1 . By eliminating $z_{t-1}$ from mutual sides of the first equation, we can write,

$$
\mathrm{V} z_{t}=\alpha z_{t-1}+y_{t}^{\prime} \delta+\varepsilon_{t}
$$

where $\alpha=\rho-1$, and t-ratio for $\alpha$ is calculated as:

$$
t_{\alpha}=\frac{\hat{\alpha}}{\operatorname{se}(\hat{\alpha})}
$$

here $\hat{\alpha}$ is the estimated parameter of $\alpha$, and $s e(\hat{\alpha})$ is the coefficient of standard error.

\section{The Kwiatkowski, Phillips, Schmidt, and Shin (KPSS) Test}

The Kwiatkowski Phillips Schmidt Shin (KPSS) is another general approach to check non-stationarity in the analysis. The hypothesis for KPSS test given as,

$$
\begin{aligned}
& H_{0} \text { : series is stationary around a deterministic trend } \\
& H_{1} \text { : unit root /non-stationary }
\end{aligned}
$$

where the KPSS statistic is defined by the following equation: 


$$
z_{t}=y_{t}^{\prime} \delta+u_{t}
$$

and the residuals are writtenas,

$$
\hat{u}_{t}=z_{t}-y_{t}^{\prime} \hat{\delta}(0)
$$

moreover, denoted as a cumulative residual function:

$$
S(t)=\sum_{r=1}^{t} \hat{u}_{r}
$$

Hence, the LM statistic is represented as:

$$
L M=\sum_{t} S(t)^{2} / T^{2} f_{0}
$$

where $f_{0}$, is an estimator of the residual scale at occurrence zero.

\section{RESULTS AND DISCUSSIONS}

Table 1 is the result for Mann-Kendall, Spearman, ADF, and KPSSin terms of p-value for Twenty-six global indices. A few notes can be built related to size each of the share price. On average, length of the daily sample is around 4300, weekly 900, and monthly 200 observations. These values just about the same due the 17 years-controlled duration each of the data sample. We first focus on determining the trend for each of the stocks in explaining price return volatility, for that MannKendall and Spearman test is utilized. The null hypothesis for Mann-Kendall test defines as the series has no trend. Meanwhile, the null hypothesis for Spearman test describes the series is independent and identically distributed. Referring on the p-value for Mann-Kendall and Spearman test, 16 stocks namely ${ }^{\wedge} \mathrm{AORD},{ }^{\wedge} \mathrm{AXJO},{ }^{\wedge} \mathrm{BSESN},{ }^{\wedge} \mathrm{BVSP}$, ${ }^{\wedge} \mathrm{FCHI},{ }^{\wedge} \mathrm{GDAXI},{ }^{\wedge} \mathrm{GSPTSE},{ }^{\wedge} \mathrm{HSI},{ }^{\wedge} \mathrm{JKSE},{ }^{\wedge} \mathrm{KS} 11,{ }^{\wedge} \mathrm{NYA}$, ${ }^{\wedge} \mathrm{RUT},{ }^{\wedge} \mathrm{STOXX} 5 \mathrm{OE},{ }^{\wedge} \mathrm{TWII},{ }^{\wedge} \mathrm{VIX}$, and ${ }^{\wedge} \mathrm{KLSE}$ display pvalue less than $\alpha=5 \%$ at all extreme return interval except for daily return signifying the existence of trend and the price return movement is affected by the time. Only three stocks which are ${ }^{\wedge} \mathrm{DJI},{ }^{\wedge} \mathrm{GSPC},{ }^{\wedge} \mathrm{IXIC}$ is significantat all interval which is daily, weekly maximum, weekly minimum, monthly maximum and monthly minimum.

Next, our analysis further inspected by checking the unit root and stationarity of the price return using ADF and KPSS test. In ADF test, the null hypothesis defined unit root is present in a time series. Unlike in KPSS test, the null hypothesis defined the series is stationary around a deterministic trend. Consulting on the p-value for ADF test, 16 stocks specifically ^ooooo1, ^AORD, ^AXJO, ^BFX, ${ }^{\wedge} \mathrm{BSESN},{ }^{\wedge} \mathrm{DJI},{ }^{\wedge} \mathrm{FCHI},{ }^{\wedge} \mathrm{GDAXI},{ }^{\wedge} \mathrm{GSPC},{ }^{\wedge} \mathrm{GSPTSE},{ }^{\wedge} \mathrm{HSI}$, ${ }^{\wedge} \mathrm{NYA}, \quad{ }^{\wedge} \mathrm{RUT}, \quad{ }^{\wedge} \mathrm{STOXX} 5 \mathrm{OE}, \quad{ }^{\wedge} \mathrm{XAX}$, and ${ }^{\wedge} \mathrm{KLSE}$ demonstrated p-value more than $\alpha=5 \%$ at all extreme return interval except for daily return suggesting that unit root is not present in the series. Closer inspection of the table 1 for $\mathrm{ADF}$ test shows ${ }^{\wedge} \mathrm{KS} 11$, and ${ }^{\wedge} \mathrm{VIX}$ appears to be the only two share market that displays existence of unit root at all interval. The non-stationarity of extreme share returns further inspected by applying statistical KPSS tests. 
Table 1. The p-value results for Mk, Spearman, ADF, and KPSS Test

\begin{tabular}{|c|c|c|c|c|c|c|c|c|c|c|c|c|c|c|c|c|c|c|c|c|c|c|c|c|c|}
\hline \multirow[b]{2}{*}{ ndice } & \multicolumn{5}{|c|}{ daily } & \multicolumn{5}{|c|}{ weekly.max } & \multicolumn{5}{|c|}{ weekly.min } & \multicolumn{5}{|c|}{ monthly.max } & \multicolumn{5}{|c|}{ monthly.min } \\
\hline & $n$ & MK & SP & ADF & KPSS & n & MK & SP & ADF & KPSS & $n$ & & SP & ADF & PSS & & MK & SP & ADF & PSS & & MK & SP & ADF & PSS \\
\hline 000001 & 4481 & 0.3989 & 0.3938 & 0.0100 & 0.1000 & 934 & 0.5025 & 0.5751 & 0.2906 & 0.0172 & 934 & 0.0275 & 0.0257 & 0.1538 & 0.0371 & 216 & 0.2463 & 0.2629 & 0.1951 & 0.0768 & 216 & 0.0737 & 0.0958 & 0.2826 & 0.1000 \\
\hline AORD & 4524 & 0.8526 & 0.9445 & 0.0356 & 0.1 & 939 & 0.0047 & 0.0063 & 0.6553 & 0.0100 & 939 & 0.0099 & 0.0061 & 0.4067 & 0.0128 & 216 & 0.0481 & 0.0311 & 0.5564 & 0.0285 & 216 & 0.0292 & 0.0094 & 0.5460 & 0.0560 \\
\hline AXJO & 4512 & 0.8526 & 0.9445 & 0.0356 & 0.1000 & 39 & 0.0047 & .0063 & 0.6553 & 0.0100 & 939 & 0.0099 & 0.0061 & 0.4067 & 0.0128 & 216 & 0.0481 & .0311 & 0.5564 & 0.0285 & 216 & 0.0292 & 0.0094 & 0.5460 & 0.0560 \\
\hline BFX & 4569 & 203 & 0.3971 & 0868 & 000 & 945 & & 7816 & 1573 & 0.0972 & 945 & 577 & 0.0746 & 785 & 0.0857 & 216 & & & 903 & & 216 & & 004 & 2699 & 000 \\
\hline ESN & 4366 & 752 & D.2946 & 0210 & 1000 & 949 & & & 2529 & .0100 & 94 & 0000 & 0.0000 & 3911 & 0.0100 & 216 & 0000 & 100 & 1494 & .00 & & 1000 & 000 & 3252 & 0100 \\
\hline BVSP & 4385 & 632 & & 100 & 1000 & 938 & 000 & 000 & 716 & 0100 & 938 & 0000 & 000 & 0766 & 0.0100 & 216 & 0000 & & 1788 & 0.0931 & 2 & 00 & & 47 & 0154 \\
\hline DJI & 4528 & 766 & 0.0743 & 0208 & 1000 & 949 & 0.0000 & .0000 & 1992 & 0.0100 & 949 & 0000 & 0.0000 & 0.1653 & 0.0100 & 216 & 0.0000 & 0.0000 & 0.2059 & 0.0201 & 216 & 0.0000 & 0.0000 & 0.3014 & 0.0170 \\
\hline $\mathrm{FCHI}$ & & & & 0453 & & 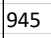 & 0051 & 0052 & & & & & & & & 21 & & & 2365 & 000 & & & & 3262 & 1000 \\
\hline DAXI & 4544 & 38 & 58 & 0498 & 00 & 939 & 000 & 000 & 650 & 0100 & 939 & 000 & 000 & 363 & 100 & 216 & 125 & 37 & 0972 & 385 & 216 & 009 & 10 & 294 & 0716 \\
\hline SPC & 4528 & & 6 & 2 & 9 & 949 & & & & 0100 & 94 & & & & & & 00 & & 2196 & 11 & & & 000 & 245 & 0415 \\
\hline GSPTSE & 4529 & 235 & 51 & 268 & 00 & 949 & 000 & 00 & 03 & 0100 & 949 & 0000 & 0000 & 0835 & 0.0100 & 216 & 0000 & 000 & 0795 & .0216 & 216 & 0016 & 0016 & 1568 & .0642 \\
\hline HIS & 4380 & 4 & 2 & 7 & 0 & 949 & 003 & 003 & 37 & 0.0100 & 945 & 01 & 001 & 80 & 0. & 216 & 001 & 02 & 834 & 66 & & 008 & 14 & 3386 & 655 \\
\hline IXIC & 4528 & 886 & & & & 949 & & & & & 949 & & & & & 21 & & & 100 & 100 & & & & 009 & 100 \\
\hline JKSE & 4247 & 967 & 6680 & 156 & 10 & 928 & 0000 & 000 & 729 & .0100 & 928 & 0000 & 0000 & 06 & 136 & 215 & 0000 & 000 & 2235 & 0100 & $t^{2}-1$ & 0000 & .0000 & 2568 & 0126 \\
\hline & & & & & & 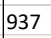 & & & & & 93 & & & & & & & & & & & & & & \\
\hline MERV & 4308 & 24 & 0 & 66 & 00 & 938 & 992 & & 38 & 1000 & 938 & 76 & 72 & 97 & 66 & 217 & 379 & 21 & 8845 & 193 & 2 & 1262 & 407 & 663 & 1000 \\
\hline MXX & 4448 & & & & & 947 & & & & 0.0 & 94 & & & & & $\left.\right|^{2}$ & & & & & & & & & \\
\hline N100 & 4581 & & & & 1000 & 945 & 179 & & & 0.0771 & 945 & 000 & 1000 & 9972 & .0224 & 216 & 1255 & 1340 & 2234 & 1000 & 2 & 0051 & .0070 & 2544 & 1000 \\
\hline N225 & & & & & & 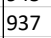 & & & & & 9 & & & & & 21 & & & & & & & & & 1000 \\
\hline NYA & 4528 & & & & & 949 & & & & & 9 & & 0000 & & & 2 & & & 11 & 66 & 2 & 63 & 98 & 16 & 963 \\
\hline RUT & 4528 & & 0. & & & 94 & & & & & 9 & & & & & 2 & & & & & & & & 2952 & 0965 \\
\hline STOX & 43 & & & & & $\log _{0}$ & & & & & 9 & & & & & 2 & & & 81 & & & 41 & & $8 / 1$ & 000 \\
\hline TWII & 4372 & & 9 & & 10 & 93 & & & 31 & & 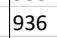 & & & 24 & & 216 & & & 2363 & & & & 000 & 1623 & 100 \\
\hline VIX & 45 & & & & & 949 & & & & & 94 & & & & & 21 & & & & & & & & 100 & 100 \\
\hline XAX & 4528 & 245 & 0.38 & 0.0396 & 0. & 949 & 0.6556 & & 0. & 0.0 & 94 & & 5523 & 170 & 42 & 216 & 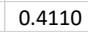 & 30 & 2 & 00 & 2 & 03 & 06 & 845 & 000 \\
\hline KLSE & 4143 & 592 & 844 & 137 & 10 & 885 & 00 & 000 & 0.3147 & 0.0100 & 8 & 000 & 000 & 678 & 100 & & 0000 & 000 & 8876 & 0100 & & 0000 & 0000 & 66 & 28 \\
\hline
\end{tabular}

Values in bold indicate that p-value is significant for the series has trend and non-stationary. MK denote Mann-Kendall and SP represent the Spearman test 
ASM Science Journal, Volume 13, 2020

\begin{tabular}{|c|c|c|c|c|c|c|}
\hline & \multicolumn{6}{|c|}{ Table 2. Summary for the existing trend and non-stationarity } \\
\hline & Test & daily & weekly.max & weekly.min & monthly.max & monthly.min \\
\hline \multirow{2}{*}{ Trend } & $\begin{array}{l}\text { Mann- } \\
\text { Kendall }\end{array}$ & $6 / 26$ & $21 / 26$ & $26 / 26$ & $22 / 26$ & $23 / 26$ \\
\hline & Spearman & $5 / 26$ & $21 / 26$ & $26 / 26$ & $21 / 26$ & $24 / 26$ \\
\hline \multirow{2}{*}{$\begin{array}{l}\text { Non- } \\
\text { Stationary }\end{array}$} & Adf & $0 / 26$ & $18 / 26$ & $17 / 26$ & $20 / 26$ & $23 / 26$ \\
\hline & Kpss & $3 / 26$ & $24 / 26$ & $26 / 26$ & $22 / 26$ & $20 / 26$ \\
\hline
\end{tabular}


The results of the KPSS test in table 2 exposed strong evidence of non-stationarity in share price return was found when 19 stocks namely ^AORD, ^AXJO, ^ BFX, ^ BSESN, ^BVSP, ${ }^{\wedge} \mathrm{DJI},{ }^{\wedge} \mathrm{FCHI},{ }^{\wedge} \mathrm{GDAXI},{ }^{\wedge} \mathrm{GSPTSE},{ }^{\wedge} \mathrm{HSI},{ }^{\wedge} \mathrm{NYA}$, ${ }^{\wedge} \mathrm{JKSE},{ }^{\wedge} \mathrm{KS} 11,{ }^{\wedge} \mathrm{MXX},{ }^{\wedge} \mathrm{NYA},{ }^{\wedge} \mathrm{RUT},{ }^{\wedge} \mathrm{TWII},{ }^{\wedge} \mathrm{VIX}$, and ${ }^{\wedge} \mathrm{KLSE}$ show that $\mathrm{p}$-value less than $\alpha=5 \%$ for all extreme return interval except for daily return. Furthermore, it is apparent from KPSS test that ${ }^{\wedge}$ GSPC and ${ }^{\wedge}$ IXIC are the only two share market demonstrates the non-stationarity behaviour at all intervals.

\section{CONCLUSION}

The primary objective of this paper was to detect the nonstationarity for the extreme series period generated from block maxima-minima approach using non-stationarity tests and trend analysis. We inspect different financial stock price return in major indices to study the general pattern behaviour, which might allow stockholders to attain more information on the return. With twenty-six set of global share price data collected from 4th January 2000 to 29th December 2017, we underline the following findings of the nonstationarity in the extreme weekly and monthly series:

i. $\quad$ For trend test analysis, at least 21 financial stock arise had a monotonic trend confirmed by MK and SR test. ii. For non-stationary analysis using ADF andKPSS test, at least 17 difference financial stock series happen to be non-stationary. On the other hand, daily series has little evidence for monotonic trend and non-stationary with only at most six financial stock has trend and three stock is non-stationary verified by trend and non-stationary test. This paper illustrates acute examination in share return series specifically for an extreme environment to reinforce the use of appropriate methods in the analysis. One cannot merely apply stationary analysis in nonstationary series as this feature may lead to offensive forecasts due to different behaviour of the stability.

In the occasion of this study, our calculations confirmed that most of the extreme stock primarily in weekly and monthly interval act as non-stationary. Anomalies and uncertainty embarking on non-stationary behaviour in the financial market is an important issue to be considered for future research. By knowing the extreme share return is nonstationary, proper mathematical models' approach when analysing the extreme share return is crucial for better comprehension.

\section{ACKNOWLEDGEMENTS}

The authors would like to thank Universiti Sains Malaysia and the Ministry of Higher Education for the scholarship handed.

\section{REFERENCES}

Behr, A. and Pötter, U. 2009, 'Alternatives to the normal model of stock returns: Gaussian mixture, generalised $\log \mathrm{F}$ and generalised hyperbolic models', Annals of Finance, 5(1), pp. 49-68. doi: 10.1007/s10436-007-0089-8.

Birău, F. R. and Trivedi, J. 2013, 'Analyzing cointegration and international linkage between Bucharest stock exchange and European developed stock markets', NAUN International Journal of Economics and Statistics, 1(4), pp. 237-246.

Black, F. and Scholes, M. 1973, 'The pricing of options and corporate liabilities', Journal of political economy. The University of Chicago Press, 81(3), pp. 637-654.
Fama, E. F. 1965, 'The Behavior of Stock-Market Prices', The Journal of Business, 38(1), pp. 34-105. doi: 10.1017/CBO9781107415324.004.

Gray, J. B. and French, D. W. 1990, 'Empirical comparisons of distributional models for stock index returns', Journal of Business Finance \& Accounting, 17(3), pp. 451-459.

Hsu, D. A. 1984, 'The behavior of stock returns: is it stationary or evolutionary?', Journal of Financial and Quantitative Analysis. Cambridge University Press, 19(1), pp. 11-28.

Hussain, S. I. and Li, S. 2015, 'Modeling the distribution of extreme returns in the Chinese stock market', Journal of International Financial Markets, Institutions and Money. 
Elsevier B.V., 34, pp. 263-276. doi: Rozelle, J. P. and Fielitz, B. D. 1980, 'Stationarity Of Common 10.1016/j.intfin.2014.11.007.

Jensen, M. C. 1969, 'Risk, the pricing of capital assets, and the evaluation of investment portfolios', The Journal of Business. JSTOR, 42(2), pp. 167-247.

Khan, T. A. 2011, 'Cointegration of international stock markets: An investigation of diversification opportunities', Undergraduate Economic Review, 8(1), p. 7.

Kon, S. J. and Jen, F. C. 1978, 'Estimation of time-varying systematic risk and performance for mutual fund portfolios: an application of switching regression', The Journal of Finance. Wiley Online Library, 33(2), pp. 457475.

Marsani, M. F., Shabri, A. and Jan, N. A. M. 2017, 'Examine generalized lambda distribution fitting performance: An application to extreme share return in Malaysia', Malaysian Journal of Fundamental and Applied Sciences, 13(3).

Masood, O. et al. 2010, 'Cointegration of Baltic stock markets in the financial Tsunami: Empirical evidence', International Journal of Business. Premier Publishing, Inc., 15(1), p. 119.

Nason, G. P. 2006, 'Stationary and non-stationary time series', Statistics in Volcanology. Special Publications of IAVCEI. Geological Society London, England, 1, p. o.

Nelson, C. R. and Plosser, C. R. 1982, 'Trends and random walks in macroeconmic time series: some evidence and implications', Journal of monetary economics. Elsevier, 10(2), pp. 139-162.

Peiro, A. 1994, 'The distribution of stock returns: International evidence', Applied Financial Economics, 4(6), pp. 431-439. doi: 10.1080/758518675.

Perron, P. 1988, 'Trends and random walks in macroeconomic time series: Further evidence from a new approach', Journal of economic dynamics and control. Elsevier, 12(2-3), pp. 297-332.

Petrică, A.-C., Stancu, S. and Ghițulescu, V. 2017, 'Stationarity-The Central Concept in Time Series Analysis'.

Petrică, A.-C., Stancu, S. and Tindeche, A. 2016, 'Limitation of ARIMA models in financial and monetary economics', Theoretical and Applied Economics. Asociatia Generala a Economistilor din Romania-AGER, 23(4 (609), Winter), pp. 19-42.

Roll, R. 1977, 'A critique of the asset pricing theory's tests Part I: On past and potential testability of the theory', Journal of financial economics. Elsevier, 4(2), pp. 129-176. 